\title{
Survival of AIDS patients using two case definitions, Rio de Janeiro, Brazil, 1986-2003
}

\author{
Dayse Pereira Campos ${ }^{\mathrm{a}}$, Sayonara Rocha Ribeiro ${ }^{\mathrm{e}}$, Beatriz Grinsztejn ${ }^{\mathrm{a}}$, \\ Valdiléa G. Veloso ${ }^{\mathbf{a}}$, Joaquim Gonçalves Valente ${ }^{\mathrm{b}}$, \\ Francisco Inácio Bastos ${ }^{c}$, Mariza Gonçalves Morgado ${ }^{d}$ and \\ Angela Jourdan Gadelhab
}

\begin{abstract}
Background: Recent studies have shown substantial increases in the survival of AIDS patients in developed countries and in Brazil as a result of antiretroviral therapy (ART) and prophylaxis for opportunistic infections. This study compares survival rates using the Brazilian Ministry of Health 2004 and Centers for Disease Control and Prevention (CDC) 1993 case definitions in a large HIV/AIDS referral centre in Rio de Janeiro.

Methods: Survival after AIDS diagnosis was assessed in a clinic-based cohort of 1415 individuals using the Kaplan-Meier method and Cox proportional hazards models.

Results: There were 393 (88\%) deaths from AIDS-related causes and 52 (12\%) from unrelated or unknown causes. A total of 205 patients (14\%) were lost to follow-up and 765 patients $(55 \%)$ remained alive until the end of the study. Three-quarters of patients (75\%) were still alive 22 months [95\% confidence interval $(\mathrm{Cl})$ 19-26] after the AIDS diagnosis according to the CDC case definition and 31 months (95\% Cl 26-36) according to the Ministry of Health case definition. Independent predictors of survival included AIDS defined by CD4 cell count and any use of highly active antiretroviral therapy, with either case definition, and initial stage of the case, with the Ministry of Health case definition.

Conclusion: Survival observed in this reference centre is comparable or longer than other international studies, although the choice of case definition criterion influenced findings. Adoption of the Ministry of Health case definition may enhance the ability to track the use of and outcomes from ART among AIDS patients.
\end{abstract}

(C) 2005 Lippincott Williams \& Wilkins

AIDS 2005, 19 (suppl 4):S22-S26

Keywords: AIDS, Brazil, case definition, highly active antiretroviral therapy, survival

\section{Introduction}

Recent studies have shown that the survival of patients with AIDS in Brazil has been increasing substantially, as observed in developed countries, mainly as a result of the universal access to antiretroviral therapy (ART) [1-4].
Several criteria have been used to define AIDS. Brazil initially used the case definition established by the Centers for Disease Control and Prevention (CDC) USA, but later adopted its own case definition, which combines an assessment of clinical conditions, the presence or absence of defining diseases and immunological status [5]. In accordance with Brazil's revised case definition, Brazilian

From the ${ }^{\mathrm{a} E v a n d r o}$ Chagas Clinical Research Institute, ${ }^{\mathrm{b}}$ National School of Public Health, ${ }^{\mathrm{c}}$ Science and Technology Information Center, and ${ }^{\mathrm{d}}$ Oswaldo Cruz Institute, Oswaldo Cruz Foundation and the ${ }^{\mathrm{e}}$ Municipal Health Department of Rio de Janeiro, STD/ AIDS Program, Rio de Janeiro, Brazil.

Correspondence to Dayse Pereira Campos, Av. Brasil, 4365, 21045-900, Rio de Janeiro, RJ, Brazil.

Tel: +55 213865 9621; fax: +55 212590 9988; e-mail: dayse@fiocruz.br 
Ministry of Health 2004, an AIDS case can be defined by a CD 4 cell count below 350 cells/ $\mu$, a level that corresponds to a status at which ART may be considered.

Most study patients have adopted the CDC case definition [6], but considering Brazil's unique position as a developing country with more than 135000 patients under ART [7], it becomes relevant to analyse the survival of these patients using both a case definition that enables comparisons with international studies and one adapted to Brazil's specific conditions. The present study makes such a comparison in a referral unit within a large biomedical research centre, the Oswaldo Cruz Foundation (FIOCRUZ), Rio de Janeiro.

\section{Methods}

A cohort of AIDS patients was followed at the Evandro Chagas Clinical Research Institute (IPEC-FIOCRUZ) between 1986 and 2002. Cases, defined by either the CDC or Ministry of Health definitions, which progressed to AIDS by 31 December 2003, were considered for the present analysis. Individuals less than 13 years of age or with less than 15 days of follow-up were excluded from the analysis.

The outcome studied was death from an AIDS-related cause. Survival was calculated as the time elapsed from the date of AIDS diagnosis until the data of death or the last attendance. Deaths from causes unrelated to AIDS, cases with loss of follow-up, and individuals who stayed alive until the end of the study period were censored at the last date documented to be alive.

The following covariates were considered: sex; education level; age at AIDS diagnosis; exposure category [8]; initial stage of disease; prophylaxis for opportunistic infections; initial and last ART; and the period when the diagnosis was made. The clinical stage of disease at the first visit was classified as AIDS and non-AIDS. For individuals who presented with more than one defining condition, a hierarchy was established such that the immunological status had primacy over the defining disease, and disease over the Ministry of Health scoring.

ART use was categorized as: monotherapy; combined therapy, when two or more nucleoside reverse transcriptase inhibitors were used; and highly active antiretroviral therapy (HAART), when at least one non-nucleoside reverse transcriptase inhibitor or protease inhibitor was used. The category 'without therapy' comprised those who died or were lost to follow-up before 1990, had no indication for therapy, or refused treatment. The period of diagnosis was categorized in relation to when antiretroviral drugs and HAART therapy were first available: up to 1990 (before ART), 1991-1995 (mono/ double therapy), and from 1996 onwards (HAART).

The survival functions were described and compared using the probabilities of survival for 1 and 5 years after AIDS diagnosis, using the Kaplan-Meier method and the log rank test [9]. The Wald test was used to define the variables to be entered into the Cox model. The stepwise method was used to fit the model, assessing the maximum likelihood in each step [10].

\section{Results}

Subjects included 1415 cases diagnosed up to 31 December 2003. Of these, 445 patients (31\%) died, 205 (14\%) were lost of follow-up, and 765 (55\%) were alive as of the end of the study. Of the cases that progressed to death, 393 (88\%) were AIDS-related and 52 (12\%) were from unrelated or unknown causes. The mean age at the baseline was 35 years. There were 468 female cases in the study (33\%). The majority of the patients had less than 8 years of education.

The Ministry of Health case definition identified 289 cases that did not meet the CDC criteria. The opposite happened in only 16 cases.

Three-quarters of patients (75\%) were still alive 22 months [95\% confidence interval (CI) 19-26] after AIDS diagnosis according to the CDC case definition and 31 months (95\% CI 26-36) according to the Ministry of Health case definition. Because the vast majority of AIDS patients were still alive at the study end, it was not possible to estimate the median length of survival using either case definition (Fig. 1).

In bivariate analysis, using either case definition: female sex; absence of baseline clinical syndrome; AIDS case definition via immunological status; prophylaxis for tuberculosis, pneumocystosis and toxoplasmosis; any use of HAART; and diagnosis after 1995 were predictors of longer survival.

In multivariate analysis, the absence of a baseline clinical syndrome and any use of HAART were predictors of longer survival for both case definitions. For the Ministry of Health criteria, the initial stage of the case was also identified as a predictor of longer survival (Table 1).

\section{Discussion}

The study highlights a substantial increase in survival after the introduction of HAART. Among international studies, the greatest survival encountered in recent years 

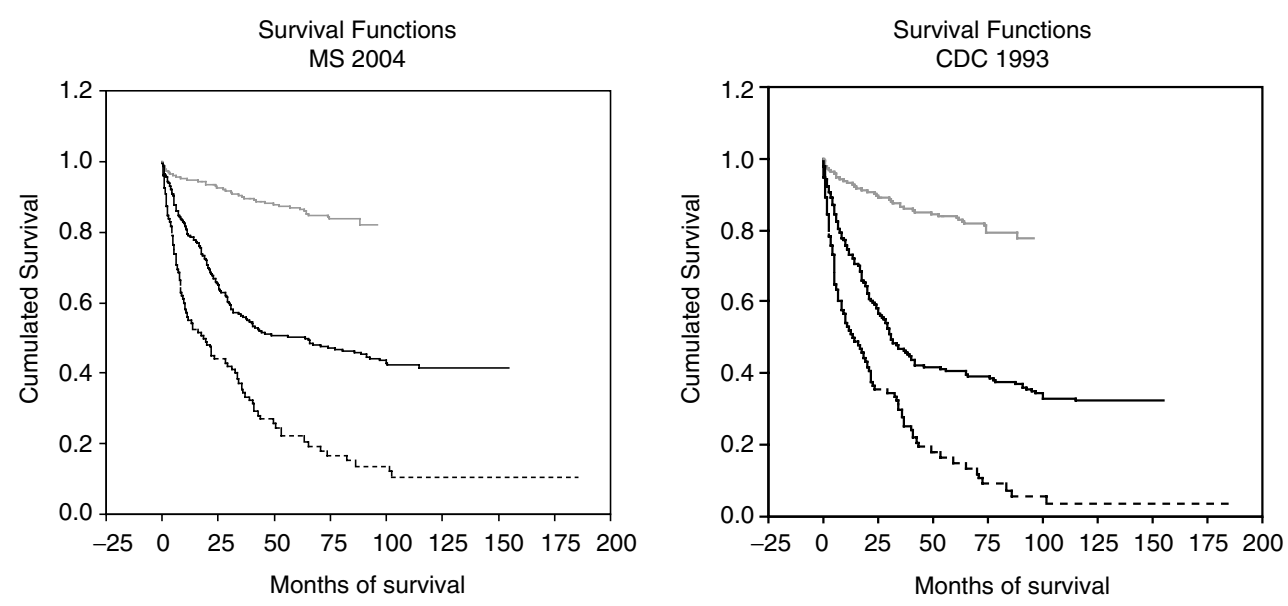

Fig. 1. Survival function for the AIDS cases according to Centers for Disease Control and Prevention 1993 and Brazilian Ministry of Health 2004 case definitions for period of diagnosis. Evandro Chagas Clinical Research Institute. Rio de Janeiro, Brazil, 1986-2003. CDC, Centers for Disease Control and Prevention; MS, Brazilian Ministry of Health. (—) 1996 and onwards, (—) 1991 to 1995, (---) up to 1990.

comes from the study by Dore et al. [11], in Australia, with cases defined between 1993 and 2000, using the CDC case definition. For patients diagnosed in 1993/ 1995 , the median survival was estimated as 20 months and 40 months for the period 1996/2000. Our findings compare favourably.

Recent studies [2,3] have already given evidence of a substantial increase in the estimated survival of individuals living with AIDS in Brazil. However, comparing the two definitions, longer survival was shown by the Ministry of Health than by the CDC criteria. These findings may be explained, partly, by using a CD4 cell cut-off of 350 cells/ $\mu 1$ in the Ministry of Health case definition rather than 200 cells/ $\mu 1$, as in the CDC case definition.

The absence of a baseline clinical syndrome and any use of HAART were shown to be associated with a greater probability of survival for both case definitions, but the initial stage of the case was found to be associated with survival only when the Ministry of Health case definition was considered.

We believe that the longer survival found in the present study, in relation to previous Brazilian studies, is mainly caused by the continuous improvement in the types and delivery of treatment. We also believe that the longer survival is partly the result of the excellence of care at the study institution. On the other hand, the findings do not seem to be associated with the initiation of antiretroviral drugs at earlier stages of immunodepression. Recent studies suggest that initiating ART at this level does not impact survival [12] as much as the effective use of antiretroviral drugs. Unfortunately, the study did not appraise antiretroviral adherence.
In the present study, the longer survival initially found for women did not remain significant in the multivariate analysis. The apparent improved survival may have been confounded by the increase in the numbers of cases among women in recent years, when the use of combined therapy or HAART and prophylaxis for opportunistic infections came into common use. Similar results were found in a study conducted in the USA in 2001 [4].

For both criteria utilized, the defining condition for AIDS determined significant differences in survival, with longer survival for cases defined by immunological status. Corroborating other studies $[4,12,13]$, the present results suggest that early follow-up, with cases defined by immunological status rather than disease allows for the timely identification of indications to initiate therapies and prophylaxis and therefore longer survival.

Survival was significantly greater for patients who had had prophylaxis for Pneumocystis jirovecii pneumonia, tuberculosis and toxoplasmosis for both case definitions. Similar results have been found in other studies conducted in Brazil that evaluated prophylaxis for Pneumocystis jiroveciii pneumonia [3,14-16].

We observed a temporal increase in survival over time in bivariate analysis. Compared with the period after 1996, the risk of death was more than ninefold for cases diagnosed up to 1990, and fourfold for the period 19911999 , for both case definitions. These results agree with those of other authors [3,4,11,17-19]. The period of diagnosis was not included in the final multivariate model because of its collinearity with the treatment using antiretroviral drugs. 
Table 1. Absolute frequency, description of the survival function, unadjusted and adjusted hazard ratio for the co-factors considered for AIDS patients, defined by the Centers for Disease Control and Prevention 1993 and Brazilian Ministry of Health 2004 criteria. Evandro Chagas Clinical Research Institute. Rio de Janeiro, Brazil. 1986-2003.

\begin{tabular}{|c|c|c|c|c|c|c|c|c|c|c|}
\hline \multirow[b]{3}{*}{ Variable } & \multicolumn{2}{|c|}{ Cases } & \multicolumn{4}{|c|}{ Probability } & \multicolumn{2}{|c|}{$\begin{array}{l}\text { Unadjusted hazard } \\
\text { ratio }\end{array}$} & \multicolumn{2}{|c|}{ Adjusted hazard ratio $(95 \% \mathrm{Cl})$} \\
\hline & \multirow{2}{*}{$\begin{array}{c}\mathrm{CDC} \\
n\end{array}$} & \multirow{2}{*}{$\begin{array}{c}\mathrm{MS} \\
n\end{array}$} & \multicolumn{2}{|c|}{1 year } & \multicolumn{2}{|c|}{5 years } & \multirow[b]{2}{*}{ CDC } & \multirow[b]{2}{*}{ MS } & \multirow[b]{2}{*}{ CDC } & \multirow[b]{2}{*}{ MS } \\
\hline & & & CDC & MS & CDC & MS & & & & \\
\hline Cohort & 1126 & 1399 & 0.82 & 0.85 & 0.61 & 0.67 & & & & \\
\hline Sex & & & & & & & $P<0.00$ & $P<0.00$ & & \\
\hline Female & 344 & 465 & 0.84 & 0.88 & 0.70 & 0.76 & 1.00 & 1.00 & & \\
\hline Male & 782 & 934 & 0.81 & 0.84 & 0.57 & 0.62 & 1.45 & 1.62 & & \\
\hline Age at time of diagnosis & & & & & & & $P>0.30$ & $P>0.50$ & & \\
\hline Less than 35 years & 529 & 686 & 0.82 & 0.86 & 0.60 & 0.67 & 1.00 & 1.00 & & \\
\hline 35 years or over & 597 & 713 & 0.81 & 0.85 & 0.62 & 0.67 & 0.95 & 1.06 & & \\
\hline Education & & & & & & & $P>0.13$ & $P>0.21$ & & \\
\hline Up to 8 years & 615 & 735 & 0.80 & 0.83 & 0.61 & 0.66 & 1.17 & 1.26 & & \\
\hline 9 or more years & 470 & 618 & 0.86 & 0.89 & 0.63 & 0.70 & 1.00 & 1.00 & & \\
\hline Category of exposure & & & & & & & $P>0.40$ & $P>0.25$ & & \\
\hline Blood & 95 & 112 & 0.78 & 0.79 & 0.61 & 0.61 & 0.99 & 1.20 & & \\
\hline Sexual & 770 & 964 & 0.81 & 0.86 & 0.59 & 0.66 & 1.00 & 1.00 & & \\
\hline Initial classification & & & & & & & $P<0.02$ & $P<0.00$ & & \\
\hline Non-AIDS ${ }^{a}$ & 552 & 831 & 0.85 & 0.90 & 0.65 & 0.74 & 1.00 & 1.00 & & 1.00 \\
\hline AIDS & 574 & 568 & 0.79 & 0.78 & 0.57 & 0.57 & 1.37 & 1.96 & & $1.83(1.10-3.06)$ \\
\hline Case definition & & & & & & & $P<0.00$ & $P<0.00$ & & \\
\hline Immunological status ${ }^{a}$ & 601 & 895 & 0.93 & 0.97 & 0.73 & 0.82 & 1.00 & 1.00 & 1.00 & 1.00 \\
\hline AIDS-defining disease & 525 & 300 & 0.69 & 0.76 & 0.47 & 0.5 & 2.53 & 3.87 & $2.09(1.26-3.48)$ & $2.03(1.14-2.63)$ \\
\hline Scoring & - & 204 & & 0.59 & & 0.40 & - & 4.63 & & $1.60(0.79-3.26)$ \\
\hline \multicolumn{11}{|l|}{ Recommended prophylaxis } \\
\hline Tuberculosis & & & & & & & $P>0.30$ & $P>0.30$ & & \\
\hline Administered & 146 & 190 & 0.76 & 0.81 & 0.56 & 0.65 & 1.00 & 1.00 & & \\
\hline Not administered & 51 & 64 & 0.71 & 0.75 & - & - & 1.00 & 1.00 & & \\
\hline PCP & & & & & & & $P<0.02$ & $P<0.03$ & & \\
\hline Administered & 716 & 894 & 0.85 & 0.88 & 0.64 & 0.7 & 1.00 & 1.00 & & \\
\hline Not administered & 174 & 214 & 0.79 & 0.83 & 0.57 & 0.63 & 1.36 & 1.34 & & \\
\hline Toxoplasmosis & & & & & & & $P<0.03$ & $P<0.01$ & & \\
\hline Administered & 471 & 589 & 0.85 & 0.87 & 0.64 & 0.69 & 1.00 & 1.00 & & \\
\hline Not administered & 90 & 109 & 0.77 & 0.83 & 0.60 & 0.67 & 1.48 & 1.55 & & \\
\hline Initial antiretroviral therapy & & & & & & & $P<0.00$ & $P<0.00$ & & \\
\hline No therapy & 210 & 268 & 0.39 & 0.42 & 0.08 & 0.13 & 17.60 & 18.45 & & \\
\hline Monotherapy & 414 & 489 & 0.84 & 0.89 & 0.51 & 0.59 & 4.60 & 4.47 & & \\
\hline Combined & 183 & 258 & 0.96 & 0.97 & 0.85 & 0.89 & 1.23 & 1.10 & & \\
\hline HAART & 319 & 384 & 0.95 & 0.96 & 0.85 & 0.88 & 1.00 & 1.00 & & \\
\hline Last antiretroviral therapy & & & & & & & $P<0.00$ & $P<0.00$ & & \\
\hline No therapy & 210 & 268 & 0.39 & 0.42 & 0.06 & 0.13 & 19.78 & 21.20 & & \\
\hline Monotherapy & 154 & 168 & 0.65 & 0.70 & 0.05 & 0.62 & 15.54 & 18.11 & $18.40(10.15-33.20)$ & $18.88(10.34-34.45)$ \\
\hline Combined & 72 & 109 & 0.79 & 0.89 & 0.26 & 0.49 & 6.93 & 4.95 & $9.03(4.54-17.65)$ & $6.40(3.20-12.80)$ \\
\hline $\mathrm{HAART}^{\mathrm{a}}$ & 690 & 854 & 0.97 & 0.98 & 0.87 & 0.90 & 1.00 & 1.00 & 1.00 & 1.00 \\
\hline Period of diagnosis & & & & & & & $P<0.00$ & $P<0.00$ & & \\
\hline Up to 1990 & 142 & 181 & 0.51 & 0.54 & 0.14 & 0.21 & 9.67 & 10.15 & & \\
\hline $1991-1995$ & 356 & 438 & 0.73 & 0.79 & 0.41 & 0.50 & 4.56 & 4.65 & & \\
\hline 1996 and onwards & 628 & 780 & 0.93 & 0.95 & 0.84 & 0.86 & 1.00 & 1.00 & & \\
\hline
\end{tabular}

CDC, Centers for Disease Control and Prevention; CI, confidence interval; HAART, highly active antiretroviral therapy; MS, Brazilian Ministry of Health; PCP, Pneumocystis jirouecii pneumonia;

${ }^{\text {a }}$ Reference category.

Our study did not examine survival from HIV diagnosis on. Survival expectations from this point should be longer because the use of treatment before diagnosis is likely to lengthen the time to AIDS. However, AIDS achieved after the initiation of treatment may be associated with severe immunosuppression and treatment failure and therefore shortened survival time after AIDS. Our study population may not be typical of other areas of Brazil. To the extent that a higher quality of care may be delivered to this population, survival may better than elsewhere.
The present findings reinforce the importance of stimulating qualified medical assistance at an early stage, with the utilization of antiretroviral and prophylactic therapy and close monitoring. It is also important to emphasize that the choice of criteria for case definition directly impacts on the results obtained. The simultaneous use of the CDC and Ministry of Health case definitions provided evidence of distinct survival lengths and allowed comparisons with international studies. 


\section{Acknowledgements}

The authors would like to thank Willi McFarland for his comments on a previous version of this manuscript, and Keyla Marzochi, Richard Moore, Luiz Alberto Matzenbacher, Claudio Vieira Lisboa, Eliane Berinqué Braga, Evilim Jashar, Kátia Valente, Cláudia Codeço, Carolina Bandeira, Dayvison Francis Freitas, Alzeny Gusmão Macedo, Ione Nascentes, Tiago de Souza Bandeira, Bruno Castelo Branco, Tatiana Nascimento, Márcio Jablonka, Renato de Noronha da Cunha, and Ieda Ramos.

Sponsorship: This study was funded by STD/AIDS Coordination Office, Ministry of Health (project no. 914/BRA/59, UNESCO, FENSPTEC no. 99047).

\section{References}

1. Fonseca LA, Reingold AL, Casseb JR, Brígidio LF, Duarte AJ. AIDS incidence and survival in a hospital-based cohort of asymptomatic HIV seropositive patients in São Paulo, Brazil. Int J Epidemiol 1999; 28:1156-1160.

2. Guerreiro MF, Kerr-Pontes LRS, Mota RS, Marcondes CF Jr, Tavora FF, Caminha I. Survival of adult AIDS patients in a reference hospital of a metropolitan area in Brazil. Revista de Saúde Pública 2002; 36:278-284.

3. Marins JR, Jamal LF, Chen SY, Barros MB, Hudes ES, Barbosa $\mathrm{AA}$, et al. Dramatic improvement in survival among adult Brazilian AIDS patients. AIDS 2003; 17:1675-1682.

4. Lee ML, Karon MJ, Selik R, Neal JJ, Fleming PL. Survival after AIDS diagnosis in adolescents and adults during the treatment era, United States 1984-1997. JAMA 2001; 285:1308-1315.

5. Brazil. Ministry of Health in Brazil. National DST/AIDS program. AIDS cases definition criteria in adults and children. Manuals Series, 60. 2004.

6. US Department of Health Human Services, Centers for Disease Control and Prevention (CDC). Impact of expanded AIDS surveillance case definition on AIDS case reporting. MMWR 1993; 16:308-311.
7. Brazil. Ministry of Health in Brazil. National DST/AIDS program. Brazilian AIDS profile and government goals for epidemic control. 2003; p. 3.

8. UNAIDS. The Joint United Nations Programs on HIV/AIDS. Abstracts of the UNAIDS 3rd Meeting of the Latin America and Caribbean Epidemiological Network. 1999; pp. 1214.

9. Kleinbaum DG. Survival Analysis - A self-learning text. Statistics in the health sciences. New York: Springer-Verlag. 1997.

10. Cox DR. Regression models and life-tables. / Roy Statistical Soc Series B 1972; 34:187-202.

11. Dore GJ, Li Y, McDonald A, Ree H, Kaldor JM. Impact of highly active antiretroviral therapy on individual AIDS - defining illness incidence and survival in Australia. J Acquir Immune Defic Syndr 2002; 29:388-395.

12. Wood E, Hogg RS, Yip B, Harrigan PR, O'Shaughnessy MV, Montaner JSG. Effect of medication adherence on survival of HIV-infected adults who start highly active antiretroviral therapy when the CD4+ cell count is 0.200 to $0.350 \times 10^{9}$ cells/l. Ann Intern Med 2003; 139:810-816.

13. CASCADE. Changes in the uptake of antiretroviral therapy and survival in people with known duration of HIV infection in Europe: results from CASCADE. Br HIV Assoc HIV Med 2000; 1:224-231.

14. Santoro-Lopes G, Harrison LH, Moulton LH, Lima LA, Pinho AM, Hofer C, Schechter M. Gender and survival after AIDS in Rio de Janeiro Brazil. I Acquir Immune Defic Syndr Hum Retrovirol 1998; 19:403-407.

15. Detels R, Muñoz A, McFarlane G, Kingsley LA, Margolick JB, Giorgi J, et al. Effectiveness of potent anti-retroviral therapy on time to AIDS and death in men with known HIV infection duration. Multicenter AIDS cohort study investigators. JAMA 1998; 280:1497-1503.

16. Brockington A, Scott GR. Trends in survival of HIV infected patients attending the Department of Genito-Urinary Medicine. Royal Infirmary of Edinburgh. Scot Med J 1997; 42:114115.

17. Dworkin MS, Hanson DL, Navin TR. The adult and adolescent spectrum HIV survival of patients with AIDS, after diagnosis of Pneumocystis carinii pneumonia, in the United States. I Infect Dis 2001; 183:1409-1412.

18. Amundsen EJ, Fekjaer $H$. Progression to AIDS slowed even more after the first two years with highly active antiretroviral therapy. Scand I Public Health 2003; 31:312318.

19. Li Y, McDonald AM, Dore GJ, Kaldor JM. Improving survival following AIDS in Australia. National HIV Surveillance Committee. AIDS 2000; 14:2349-2354. 